\title{
The intrusiveness of familiar nontarget information
}

\author{
WILLIAM A. JOHNSTON \\ University of Utah, Salt Lake City, Utah 84112
}

\begin{abstract}
Two experiments required subjects to attend to one of two binaurally presented passages and, at the same time, perform a visual reaction time (RT) task. Mean RT measured the capacity expended on selective listening: Longer RTs imply greater capacity expenditure. The relative familiarity of target and nontarget passages and the cue by which they could be differentiated (sensory vs. semantic) were manipulated. The target passages were defined by the experimenter in Experiment 1 but chosen by the subjects in Experiment 2. Both experiments showed that expenditure of capacity increased from sensory to semantic selection and increased with nontarget familiarity only for semantic selection. The data were interpreted in terms of a multimode theory of attention.
\end{abstract}

The present experiments examined the intrusiveness or disruptive impact of familiar nontarget information on selective listening to target information. The issue of nontarget instrusiveness can be couched within the framework of the multimode theory of attention developed by Johnston and Heinz (in press, Note 1, Note 2). I will first provide a brief sketch of multimode theory and then bring it to bear on the question of nontarget intrusiveness.

According to multimode theory, an individual can assume different positions on a continuum of attention modes that ranges from early selection to late selection. As the continuum is ascended, target and nontarget inputs are differentiated at progressively higher or deeper levels of perceptual analysis. Target information is discriminated from nontarget information after minimal sensory analysis at the early-mode end of the continuum, and after rather extensive sensory and semantic analysis at the late-mode end. Early modes simulate the essential properties of the original filter theory of Broadbent (1958), and late modes simulate the essential properties of the late-selection theory of Deutsch and Deutsch (1963). As the continuum is ascended, breadth of attention is purchased at a commensurate cost in selection efficacy: The processing system becomes more sensitive to the properties of nontarget information and less adept at focusing exclusively on target information.

Johnston and Heinz (in press, Note 1, Note 2) have deployed a selective listening task to the testing of multimode theory. Subjects received binaurally presented passages (both passages to both ears) and had

I would like to thank Steven P. Heinz for his assistance in this research. Portions of this research were presented at the meeting of the Psychonomic Society, Boston, November 1974. Requests for reprints should be sent to William A. Johnston, Department of Psychology, University of Utah, Salt Lake City, Utah 84112. to attend to (e.g., shadow) the one predesignated as the target passage. Target and nontarget passages differed either in sensory quality (e.g., male vs. female voices) or in semantic content (e.g., names of animals vs. names of cities). A sensory cue allowed early selection and a semantic cue necessitated later selection. Measures were taken of the accuracy and effort of selective listening (selection efficacy) and the incidental memory of nontarget inputs (breadth of attention). Effort was measured in terms of reaction time to subsidiary light signals: Reaction time (RT) is assumed to be directly related to the capacity or effort invested on selective listening. In confirmation of multimode theory, sensory cues yielded greater selection efficacy but semantic cues yielded greater breadth of attention.

As breadth of attention increases from early- to latemode conditions, the selective processing of target information should become more sensitive to particular characteristics of coincident nontarget information. For example, a semantic relationship between targets and nontargets has been found to influence the efficacy of target selection more under late-mode conditions than under early-mode conditions (Underwood, 1976; Johnston \& Heinz, Note 1, Note 2). Similarly, the density or volume of nontarget inputs has been found to affect late-mode selection more than early-mode selection (Johnston \& Heinz, in press, Experiment 5; Schneider \& Shiffrin, 1977, Experiments 1 and 2). The present experiments examined the effect of nontarget familiarity on the efficacy of sensory (earlymode) and semantic (late-mode) selection. A highly familiar nontarget input should tend to yield an "automatic attention response" (Shiffrin \& Schneider, 1977 ) or be captured by the "top-down" biases of the system (Norman \& Bobrow, 1976) and thereby subrogate a simultaneous target input for admission into consciousness. However, an early mode of attention should be capable of suppressing the 
perceptual processing of even familiar nontarget inputs, thereby protecting them from top-down biases and circumventing their intrusiveness. Hence, the principal hypothesis tested is that nontarget familiarity should affect efficacy of semantic selection more than efficacy of sensory selection. The main index of selection efficacy was the amount of capacity expended on the selection task.

\section{EXPERIMENT 1}

\section{Method}

Tasks, apparatus, and materials. Experimental conditions required subjects to perform two task $s$ at the same time: a primary selective listening task and a subsidiary RT task. The selective listening task entailed the binaural presentation of two passages. The target passage began $10 \mathrm{sec}$ ahead of the nontarget passage so that subjects could gear their attentional machinery to the target passage. The two passages coincided for about $60 \mathrm{sec}$. At the conclusion of a trial, a true-false question was asked about the target passage. All passages were presented in a normal reading manner at around $65 \mathrm{~dB}$ and at the rate of 120 words $/ \mathrm{min}$. The RT task was used to measure the capacity or effort expended on the listening task: Longer RTs imply greater expenditure of capacity. Subjects pushed a button upon detecting a brief $(500-\mathrm{msec})$ increment in the intensity of a light source. The standard intensity was $8 \mathrm{fL}$ and the signal intensity was $32 \mathrm{fL}$. A signal occurred at a random point in each 10 -sec interval (signal interval) of a trial, with the restriction that the minimum interval between signals be $3 \mathrm{sec}$.

Subjects served individually in a sound-deadened cubicle equipped with a stereo headset, microphone, signal light, and response button. The experimenter station was located directly outside the subject's cubicle and contained two stereo tape recorders, amplifiers, a sound-sensitive relay, and a PDP-8E computer. one of the tape recorders presented passages to the subject's headset from one channel and a noise burst to the computer from another channel. The noise burst coincided with the onset of a trial, closed the sound-sensitive relay, and signaled the computer to program and present light signals. The second tape recorder was used to record the subject's responses to the true-false questions.

The passages were excerpted from various introductory psychology textbooks. Those designated as target passages were approximately 140 words in length, and those designated as nontarget passages were approximately 120 words in length. The difference in passage length was needed to allow for the 10 -sec lead time of target passages.

Subjects and procedure. The subjects were 66 male and female subjects who received extra credit toward a higher grade in an introductory psychology class for their participation. Subjects served for about $40 \mathrm{~min}$ on each of 2 consecutive days. The first session was a practice session in which subjects were familiarized with the tasks and with six particular passages. Subjects received 1 familiarization trial on five of the passages and 15 on the sixth passage. The former passages were to serve as moderately familiar (MF) passages on Session 2 and the latter passage was to serve as a highly familiar (HF) passage. Subjects were asked to paraphrase the passage after each familiarization trial.

The second session was comprised of five trials under each of five listening conditions. The RT task was involved in all conditions. However, no listening was required in one control condition (OL), and listening to a single unfamiliar passage was required in another control condition (U). The remaining three conditions required selective listening to an unfamiliar target passage. The nontarget passage was also unfamiliar in
Condition U-U, but was moderately familiar in Condition U-MF, and was highly familiar in Condition U-HF. A passage rotation scheme insured that, across subjects, each nontarget passage served a $\mathrm{U}, \mathrm{MF}$, and $\mathrm{HF}$ function equally often. Three different random orderings of the five conditions across the 25 trials of Session 2 were used equally often. The intertrial interval was $10 \mathrm{sec}$.

Subjects were evenly divided into two groups: semantic selection and sensory selection. All of the target passages were recorded in a particular female voice. The nontarget passages were recorded in the same voice for semantic-selection subjects, but in a particular male voice for sensory-selection subjects. ${ }^{1}$ Thus, subjects were restricted to the use of semantic cues for distinguishing between target and nontarget passages in the semantic-selection group, but could use sensory cues (voice quality) in the sensory-selection group.

In summary, the experimental design comprised selection cue (sensory vs. semantic) as a between-subjects variable and listening condition (OL, U, U-U, U-MF, and U-HF), trial (1-5), and signal interval (six $10-\mathrm{sec}$ intervals per trial) as withinsubjects variables.

\section{Results and Discussion}

The 5\% level of significance was used for all statistical tests reported in this paper. Preliminary analyses revealed that neither trial nor signal interval had any diagnostic value. Hence, the units of analysis for the tests reported below represent averages over trials and signal intervals. The first signal intervals were excluded from the averages in order to eliminate RTs measured during the target-lead portions of selective listening trials.

The rate of missed RT signals was $6 \%$ overall and tended to covary across conditions with mean RT for detected signals. As Table 1 reveals, the mean RT data were in precise accord with the expectations derived from multimode theory. An analysis of variance of these data showed all three experimental sources of variance to be statistically significant $[\mathrm{F}(1,65)=4.98$, $\mathrm{MSe}=13,091$ for selection cue; $F(4,256)=153.09$, $\mathrm{MSe}=588$ for listening condition; and $\mathrm{F}(4,256)=7.39$, $\mathrm{MSe}=588$ for the interaction]. A Newman-Keuls test (Winer, 1962) of the means defining the interaction illuminated the theoretical thrust of the results. First, the sensory- and semantic-selection groups differed only with respect to those listening conditions under which they received different treatment, namely, the selective listening conditions (U-U, U-MF, and U-HF). More importantly, the pattern of mean RT across listening conditions differed markedly for the two groups $(\mathrm{OL}<\mathrm{U}<\mathrm{U}-\mathrm{U}=\mathrm{U}-\mathrm{MF}=\mathrm{U}-\mathrm{HF}$ for sensory

Table 1

Mean Reaction Time in Experiment 1 as a Function of Selection Cue and Listening Condition

\begin{tabular}{cccccc}
\hline & \multicolumn{5}{c}{ Listening Condition } \\
\cline { 2 - 6 } $\begin{array}{c}\text { Selection } \\
\text { Cue }\end{array}$ & OL & U & U-U & U-MF & U-HF \\
\hline Sensory & 304 & 368 & 379 & 373 & 387 \\
Semantic & 309 & 369 & 401 & 414 & 434 \\
\hline
\end{tabular}

Note-Each mean is based on 990 observations. 
selection and $\mathrm{OL}<\mathrm{U}<\mathrm{U}-\mathrm{U}<\mathrm{U}-\mathrm{MF}<\mathrm{U}-\mathrm{HF}$ for semantic selection). Thus, attention required capacity $(\mathrm{U}<\mathrm{U}-\mathrm{U})$ in both groups, but the amount required increased with nontarget familiarity only in the semantic-selection group.

True-false accuracy was $81 \%$ overall and did not vary reliably with any of the experimental manipulations. However, the true-false test was intended primarily to motivate subjects to perform the listening task and not to measure selection efficacy. Since listening accuracy has proven sensitive to selection cue in numerous prior studies (see Johnston \& Heinz, Note 1 , for a review), it is likely that the true-false test in the present study was not a sensitive measure of listening accuracy.

In any case, the component of selection efficacy on which this research focused (viz., capacity expenditure) does seem to be differentially sensitive to nontarget familiarity at different points on the continuum of attention modes. The capacity required to listen selectively to an unfamiliar target passage is relatively low and independent of the familiarity of the nontarget passage when an early mode of attention is employed, but is relatively high and increases with the familiarity of the nontarget passage when a later mode is employed. Evidently, top-down influences are relatively impotent when the bottom-up data on which they operate are systematically suppressed.

\section{EXPERIMENT 2}

The second experiment sought to extend the generality of the findings of the first experiment to a situation in which subjects are free to attend to their choice of two simultaneous passages. Experiment 1 demonstrated that the intrusiveness of a familiar nontarget passage increases as the continuum of attention modes is ascended. Hence, in a free choice situation, selection efficacy should be more dependent on the relative familiarity of the selected and rejected passages under a late-mode condition than under an early-mode condition. Moreover, subjects should be more likely to choose to attend to the more familiar passage, and thereby obviate the problem of nontarget intrusiveness, under a late-mode condition than under an early-mode condition. Therefore, the principal expectations in Experiment 2 were that the likelihood of choosing the more familiar of two passages would be greater under semantic selection than under sensory selection, and that selection efficacy would be more dependent on the passage chosen under semantic selection.

\section{Method}

Experiment 1 was replicated with the following exceptions: The sensory- and semantic-selection groups each contained 48 subjects; the MF passages were eliminated; the $O L$ and $U$ conditions were run on Session 1; and a free choice procedure was instituted on Session 2. Session 2 encompassed 15 trials. Both passages were unfamiliar on 5 of the trials $(\mathrm{U}, \mathrm{U})$, and one was unfamiliar and the other familiar on 10 of the trials (U,HF). The two passages always began at the same time and lasted for about $1 \mathrm{~min}$. Subjects were instructed to select one of the two passages and follow it to the end of the trial. At the conclusion of a trial, subjects gave a brief description of the passage to which they attended and then estimated the percentage of the passage that they managed to comprehend.

\section{Results and Discussion}

Percentage of HF choices, mean RT, and mean comprehension estimates will be examined in that order. Performance measures were averaged over trials and signal intervals as these variables again proved to be of no diagnostic value.

As expected, the percentage of HF choices on the 10 trials involving the HF passage was greater in the semantic-selection group (66\%) than in the sensoryselection group $(39 \%)[\mathrm{F}(1,94)=38.37, \mathrm{MSe}=4.04]$. Hence, there was a bias toward the HF passage in the late-mode condition and one of nearly equal strength against the HF passage in the early-mode condition. The bias toward the $U$ passages in the sensory-selection condition was not anticipated, but, in retrospect, makes sense. The $U$ passages were more novel and, therefore, probably more interesting than the HF passage. Apparently, the intrusiveness of the HF passage in the late-mode condition outweighed the interest value of the U passages in determining passage choice.

The RT comprehension data are summarized in Table 2. The rate of missed RT signals again was about $6 \%$ overall and tended to covary with mean RT. Preliminary analyses of mean RT revealed $\mathrm{OL}<\mathrm{U}=\mathrm{U}, \mathrm{U}$ for the sensory-selection group and $O L<U<U, U$ for the semantic-selection group. Thus, relative to nonselective listening $(\mathrm{U})$, selective listening $(\mathrm{U}, \mathrm{U})$ required capacity only in the late-mode group. Primary interest centered on Conditions U,U, HF-U (HF chosen), and U-HF (U chosen). ${ }^{2}$ Only selection cue $[\mathrm{F}(1,94)=12.55, \mathrm{MSe}=8,488]$ and Selection Cue by

Table 2

Mean Reaction Time and Mean Comprehension Estimate in Experiment 2 as a Function of Selection Cue and Listening Condition

\begin{tabular}{|c|c|c|c|c|c|c|}
\hline \multirow[b]{2}{*}{ Measure } & \multirow{2}{*}{$\begin{array}{l}\text { Selection } \\
\text { Cue }\end{array}$} & \multicolumn{5}{|c|}{ Listening Condition } \\
\hline & & $\mathrm{OL}$ & $\mathrm{U}$ & $\mathrm{U}, \mathrm{U}$ & HF-U & U-HF \\
\hline Mean RT* & Sensory & 301 & 370 & 378 & 384 & 385 \\
\hline & Semantic & 308 & 378 & 419 & 418 & 433 \\
\hline Comprehension** & Sensory & & & 67 & 76 & 69 \\
\hline Estimate (Percent) & Semantic & & & 51 & 67 & 42 \\
\hline
\end{tabular}

Note-Conditions $H F-U$ and $U-H F$ represent trials in which the $H F$ and $U$ passages, respectively, were chosen.

* Each mean is based on from 893 (semantic selection, U-HF) to 1,987 (semantic selection, HF-U) observations.

**Each mean is based on from 149 (semantic selection, U.HF) to 331 (semantic selection, $H F-U$ ) observations. Comprehension estimates were not applicable to Condition $O L$ and not taken in Condition $U$. 
Listening Condition $[F(2,188)=5.15, \quad M S e=733]$ attained significance in an analysis of variance of mean RT in these conditions. A Newman-Keuls test of the interaction indicated $\mathrm{U}, \mathrm{U}=\mathrm{HF}-\mathrm{U}=\mathrm{U}-\mathrm{HF}$ for the sensory-selection group, but $\mathrm{U}, \mathrm{U}=\mathrm{HF}-\mathrm{U}<\mathrm{U}-\mathrm{HF}$ for the semantic-selection group. Thus, the principal results that were obtained under the forced choice procedures of Experiment 1 were duplicated under the free choice procedures of Experiment 2. The effort required to attend to an unfamiliar passage was not affected by nontarget familiarity when a sensory cue was available, but was a direct function of nontarget familiarity when only a semantic cue was available.

All three experimental sources of variance attained significance in an analysis of mean comprehension estimates. ${ }^{3}$ Sensory selection yielded higher comprehension estimates than semantic selection $[F(1,94)=32.95$, $\mathrm{MSe}=619 \mathrm{]}$, and comprehension estimates tended to be relatively high in Condition HF-U and low in Condition U-HF $\quad[\mathrm{F}(2,188)=57.86, \quad \mathrm{MSe}=115]$. However, the effect of listening condition varied with selection cue $[F(2,188)=7.42, \mathrm{MSe}=115]$. A NewmanKeuls test revealed HF-U>U,U $=U$-HF for sensory selection and HF.U $>$ U,U $>$ U-HF for semantic selection. Naturally, the HF passage was rated as relatively comprehensible regardless of mode of selection. More importantly, the rated comprehensibility of a $U$ passage was not affected by nontarget familiarity in the sensory-selection group but was an inverse function of nontarget familiarity in the semanticselection group.

In summary, sensory selection can be directed to the less familiar, and presumably more interesting, of two passages without sacrificing selection efficacy. However, semantic selection can be so directed only at a definite cost in selection efficacy. It stands to reason, therefore, that sensory-selection subjects tend to choose the less familiar passages, while semanticselection subjects opt for the more familiar passages.

\section{GENERAL DISCUSSION}

The RT data confirm the basic results of Johnston and Heinz (in press). Averaging over conditions and experiments, the pooled capacity requirements of all the processes entailed by listening to a single passage was about $66 \mathrm{msec}(\mathrm{U}>\mathrm{OL})$. The additional capacity needed to select the target passage of two passages $(U \cdot U>U)$ was about $10 \mathrm{msec}$ for sensory selection and $36 \mathrm{msec}$ for semantic selection. Thus, attention requires capacity and the amount required increases from early to late modes.

The present results extend those of Johnston and Heinz (in press) in showing that late modes are more sensitive than early modes to the familiarity of nontarget inputs. The capacity expended on selective listening was independent of nontarget familiarity when a sensory cue was provided, but was a direct function of nontarget familiarity when only a semantic cue was provided. This result held true whether the target and nontarget passages were chosen by the experimenter (Experiment 1) or by the subjects (Experiment 2). The interaction obtained between selection cue and nontarget familiarity indicates that breadth of attention increases from early to late modes of selection.

The present results together with prior results (see Johnston \& Heinz, Note 1, for a review) make a strong case for multimode theory. The human processing system appears to have access to a continuum extending from early selection à la Broadbent (1958) to late selection à la Deutsch and Deutsch (1963). Early modes allow for efficacious selection of target inputs but sharply curtail the perceptual processing of nontarget inputs. Late modes prohibit efficacious selection of target inputs but allow for relatively deep perceptual processing of nontarget inputs. Hence, as the continuum is ascended, breadth of attention is purchased at a commensurate cost in selection efficacy.

The optimal locus of operation on the continuum should vary with the prevailing circumstances. Late modes were nonoptimal under the U.HF conditions of the present research because they allowed HF passages to be inappropriately picked up by top-down biases and interfere with the selective processing of $\mathrm{U}$ passages. However, late modes should become more optimal as the importance of breadth of attention approaches or exceeds that of selection efficacy; for example, during a war-time night patrol in an enemyinfested area, or during a boring conversation at a cocktail party.

\section{REFERENCE NOTES}

1. Johnston, W. A., \& Heinz, S. P. A multimode analysis of attention. Manuscript submitted for publication, 1977.

2. Johnston, W. A., \& Heinz, S. P. Attention: An integrative conceptual frumework. Paper presented at the meeting of the Psychonomic Society. Saint Louis, November 1976.

\section{REFERENCES}

Broadbent. D. E. Perception and communication. London: Pergamon Press, 1958.

Deutsch. J. A. \& Deutsch, D. Attention: Some theoretical considerations. Psychological Review, 1963, 70. 80-90.

Johnston. W. A.. \& Heinz, S. P. The flexibility and capacity demands of attention. Journal of Experimental Psychology: General, in press.

Norman, D. A.. \& Bobrow. D. G. On the role of active memory processes in perception and cognition. In $C$. $\mathbf{N}$. Coter (Ed.). The structure of human memory. San Francisco: Freeman. 1970.

Schneider, W., \& Shiffrin, R. M. Controlled and automatic human information processing: I. Detection, search and attention. Psychological Review, 1977, 84. 1-bo. 
Shiffrin. R. M.. \& Schneider, W. Controlled and automatic human information processing: II. Perceptual learning, automatic attending, and a general theory. Psychological Revieu, 1977, 84, 127-190.

UNDERWOOD, G. Semantic interference from unattended printed words. British Journal of Psychology, 1976. 67. 327-338.

WINER. B. J. Statistical principles in experimental design. New York: McGraw-Hill, 1962.

\section{NOTES}

1.Prior research has shown that the data are unaffected by which voice (male or female) is designated as the target voice (Johnston \& Heinz, in press, Experiment 4).

2. Only four semantic-selection subjects failed to choose the $\mathrm{U}$ passage on any of the trials involving the HF passage, and only one sensory-selection subject failed to choose the HF passage on any of these trials. These five subjects were assigned the mean RT for the subjects in their groups who did make the designated choices.

3. Comprehension estimates are subject to at least two interpretations. They could directly reflect the extent to which subjects actually comprehended the passages to which they paid attention. Alternatively, they could be inferences drawn by subjects on the basis of the apparent effort expended on attending. In any event, the comprehension data are only supplementary to the main index of selection efficacy, namely, mean RT.
(Received for publication August 4, 1977 ; accepted September 30, 1977.) 